\title{
Recombinant human growth hormone in the treatment of Turner syndrome
}

\author{
Bessie E Spiliotis \\ Division of Pediatric Endocrinology \\ and Diabetes, Department of \\ Pediatrics, University of Patras, School \\ of Medicine, Patras, Greece
}

\begin{abstract}
Turner syndrome (TS) is a common chromosomal disorder in women that is associated with the absence of one of the $\mathrm{X}$ chromosomes. Severe short stature and a lack of pubertal development characterize TS girls, causing psychosocial problems and reduced bone mass. The growth impairment in TS seems to be due to multiple factors including an abnormal growth hormone (GH) - insulin-like growth factor (IGF) - IGF binding protein axis and haploinsufficiency of the short stature homeobox-containing gene. Growth hormone and sex steroid replacement therapy has enhanced growth, pubertal development, bone mass, and the quality of life of TS girls. Recombinant human GH (hGH) has improved the height potential of TS girls with varied results though, depending upon the dose of hGH and the age of induction of puberty. The best final adult height and peak bone mass achievement results seem to be achieved when hGH therapy is started early and puberty is induced at the normal age of puberty in a regimen mimicking physiologic puberty. The initiation of estradiol therapy at an age-appropriate time may also help the TS patients avoid osteoporosis during adulthood. Recombinant hGH therapy in TS seems to be safe. Studies so far show no adverse effects on cardiac function, glucose metabolism or any association with neoplasms but research is still in progress to provide conclusive data on long-term safety.
\end{abstract}

Keywords: Turner syndrome, recombinant growth hormone, growth hormone deficiency, SHOX gene, hormonal replacement therapy

\section{Introduction}

Turner syndrome (TS), the most common chromosomal disorder in women, results from the partial or complete absence (monosomy) of one of the $\mathrm{X}$ chromosomes. TS affects one in 2500 live female births and it may exist without (nonmosaic form) or with the presence (mosaic form) of a normal 46 XX or, rarely, a 46XY cell line. Abnormalities such as ring $\mathrm{X}$ and $\mathrm{Xq}$ isochromosomes are common in patients with classic TS features and many of these girls have phenotypes indistinguishable from those of girls with nonmosaic monosomy X. A variety of physical characteristics are present in TS. Short stature, ovarian dysgenesis and ovarian failure are the most prevalent abnormaliites. Streak gonads in TS are common and the girls with TS usually do not show any signs of breast development. Some girls with TS though have spontaneous puberty and manifest normal breast development. Other physical features of TS include facial dysmorphism with low-set ears, webbed neck, short neck, low-set hair-line, "shield chest" with an increased distance between the pre-pubertal breasts, cardiovascular defects, cubitus valgus, renal malformations, hearing loss and lymphedema (Nielsen and Wohlert 1991). Cognitive deficits involved with nonverbal learning abilities and visuospatial skills and behavioral problems may also be present in TS (Rovet 2004).

Girls with TS many times manifest only very subtle physical features of TS of which short stature is the most prominent, even from a young age. Therefore, it is recommended that all girls with short stature and/or growth delay for which no medical 
reason can be found to have a karyotype performed in order to investigate the possibility of the presence of TS (Nielsen and Wohlert 1991).

\section{Growth}

Girls with TS are born with intrauterine growth retardation and they exhibit growth failure during early childhood as early as 1 year of age. The growth delay worsens during puberty, because of the absence of the pubertal growth spurt, resulting in a strikingly short adult height approximately $20 \mathrm{~cm}$. shorter than the mean adult height of normal women. Spontaneous puberty occurs in $10 \%$ to $20 \%$ of the girls with TS accompanied by a small pubertal growth spurt but prepubertal growth and final adult height in these cases are similar to those of TS girls without spontaneous puberty (Massa et al 1990).

In the past, it was thought that the etiology of the short stature in TS was due to a reduction in spontaneous growth hormone (GH) secretion. This was because 24-hour (24 h) GH studies in girls from the age of 9 to 20 years of age showed decreased mean $24 \mathrm{~h} \mathrm{GH}$ concentrations (Lyon et al 1985). After the observation though that estradiol amplifies the neuroendocrine regulation of pulsatile GH release in normal pubertal girls (Ho et al 1987) it became evident that this decrease in the $24 \mathrm{~h} \mathrm{GH}$ concentrations in the pubertalaged TS girls was due to their lack of estradiol. Estrogen replacement therapy in pubertal-aged TS girls normalizes the $24 \mathrm{~h}$ integrated concentrations of $\mathrm{GH}$, but the growth deficit is still present in these girls (Zadik et al 1992). The growth impairment in the majority of TS individuals therefore, is not due to GH deficiency although a small minority of TS girls may manifest classic GH deficiency (abnormal GH concentrations after pharmacologic provocation) in addition to their abnormal karyotype. Pharmacologic provocation tests though, are not recommended unless the girl's growth is clearly abnormal relative to that expected for TS determined by plotting lengths and heights on TS-specific growth curves (Rongen-Westerlaken et al 1997; Bondy 2007).

Despite the fact that GH deficiency is not usually present in TS, the GH - insulin-like growth factor (IGF) - IGF binding protein (IGFBP) axis is disturbed. Increased IGFBP3 proteolytic activity has been found in adult TS combined with low levels of circulating free IGF-I and increased levels of free IGF-II. Normal formation of the $150 \mathrm{kDa}$ IGFBP-3 ternary complex ( acid-labile subunit (ALS), IGF-I and IGFBP-3) is also disrupted in TS, together with decreased levels of intact IGFBP-1,- 2, and -4, and decreased bioactive IGF-I. These occur despite the presence of normal immunoreactive levels of total IGF-I, IGFBP-1, $-2,-3$ and -4 and ALS
(Gravholt et al 2001). A sex hormone dependent IGFBP-3 protease (serine protease) seems to lead to destabilization of the $150 \mathrm{kDa}$ IGFBP-3 ternary complex in TS since hormone replacement therapy (HRT) with estrogen causes a marked reduction in IGFBP-3 proteolysis, suggesting modulation of the protease by sex hormones. Concurrently after HRT in TS, free IGF-II decreases while free IGF-I remains unchanged. The binary complex of IGF-I and IGFBP-1 increases in response to HRT, the proteolysis of IGFBP-3 normalizes, and accordingly leads to normalization of ternary complex formation (Gravholt et al 2006).

In 1997, haploinsufficiency for the short stature homeoboxcontaining gene (SHOX) was found to also contribute to the marked short stature found in TS (Rao et al 1997; Rao et al 2001). The SHOX gene is located on the distal end of the $X$ and $Y$ chromosomes at Xp22.3 and Yp11.3 in the pseudoautosomal region 1 (Marchini et al 2004; Munns et al 2004). It is essential for the regulation of chondrocyte proliferation and differentiation and it encodes a cell-type specific nuclear transcriptional activator, primarily expressed in osteogenic cells (Rao et al 2001). SHOX acts as a repressor of growth plate fusion since it is specifically expressed in the growth plate in hypertrophic chondrocytes undergoing apoptosis (Marchini et al 2004; Munns et al 2004). The haploinsufficiency of the SHOX gene may lead to premature growth plate fusion in the distal limbs in TS and it influences the short stature of XO females since two copies of this gene are required for normal height (Blaschke 2006). Individuals with SHOX deficiency have variable degrees of growth impairment with or without a spectrum of skeletal anomalies (Blum et al 2007). A wide spectrum of abnormalities are associated with mutations or deletions of the SHOX gene ranging from short stature without dysmorphic abnormalities to a form of short stature characterized by disproportionate shortening of the forearms and lower legs, cubitus valgus, Madelung deformity, short fourth metacarpals and high-arched palate (Binder et al 2003). This skeletal anomaly is typically observed in patients with Leri-Weill syndrome and to a lesser degree in TS patients (Ogata 1993). It is noteworthy to add though, that the degree of short stature observed with simple haploinsufficiency for the SHOX gene is not as severe as that observed in TS patients suggesting that haploinsufficiency for additional genes located on the short arm of the $\mathrm{X}$ chromosome also contribute to the growth retardation seen in TS (Ogata et al 1993; Zinn et al 2000; Rosenfeld 2007).

A recent study suggests that haploinsufficiency of one or more genes in Xp22.3, the distal 8.3 megabases $(\mathrm{Mb})$ of the $\mathrm{X}$ chromosome, is also responsible for the TS neurocognitive 
phenotype which includes impaired visual-spatial abilities (Zinn et al 2007). This interval includes the 2.6 Mb Xp-Yp pseudoautosomal region (PAR1) but the study suggests that haploinsufficiency of the SHOX gene does not cause TS neurocognitive phenotype.

\section{Psychosocial status}

Another view advocated by some researchers, is that the abnormal adult height in women with TS is a complex qualitative trait associated with additional genes that have not yet been identified, and with aneuploidy or other forms of chromosomal imbalance, as is present in chromosomal disorders such as Down's syndrome (Haverkamp et al 1999).

\section{Growth hormone therapy}

Treatment of the short stature in TS has been historically based on psychosocial issues since it is not evident that there is an advantageous organic health benefit by being taller with TS. Psychological studies of children with TS report that their short stature is most often associated with social competence. Shorter TS children are less competent socially and at a greater risk of social impairment with social isolation and social ineptitude probably because of teasing and stigmatization by their peers (Rovet et al 1994).

Recombinant human $\mathrm{GH}(\mathrm{hGH})$ therapy is now routinely used to treat the growth impediment in girls with TS although many studies have shown varied results. Comparisons of the studies of the final adult heights (FHA) of women with TS who were treated with hGH show height gains after treatment ranging from no significant increase over the projected adult height (PAH) (Dacou-Voutetakis et al 1998), significant increases of $5 \mathrm{~cm}$ or more over the PAH (Taback et al 1996; Chu et al 1997; Carel et al 1998; Plotnick et al 1998; Rosenfeld et al 1998; Chernausek et al 2000; Ranke et al 2000; Reiter et al 2001; Quigley et al 2002; van Pareren et al 2003; Massa et al 2003; The Canadian Growth Hormone Advisory Committee 2005) to a mean height gain over the PAH of up to $16 \mathrm{~cm}$ using a higher dose of hGH $(\sim 0.630 \mathrm{mg} / \mathrm{kg} /$ week) (Sas et al 1999a). The multicenter Canadian study (The Canadian Growth Hormone Advisory Committee 2005) employed a parallel, randomized control group that received no hGH and was followed to adult height showing a mean height gain due to $\mathrm{GH}$ of $+7.2 \mathrm{~cm}$. Also, the largest TS study to date which included 5500 TS patients, of which 1146 TS patients were treated to adult height using an hGH dose of $0.28 \pm 0.08 \mathrm{mg} / \mathrm{kg} /$ week, reported a height SDS at the beginning of hGH treatment of $-3.1 \pm 0.9$ and at adult height an SDS of $-2.3 \pm 1.1$ (Ranke et al 2007).
To overcome the retarded growth in TS patients most studies have shown that high doses of hGH are needed inducing sometimes "acromegalic" levels of IGF-I, suggesting the presence of GH or IGF-I resistance in the bones (Van Pareren et al 2003; Bannink et al 2006a). Which hGH dose to use is still an issue of debate but recombinant hGH therapy is usually started at the recommended dose of $0.375 \mathrm{mg} / \mathrm{kg} /$ week divided into daily injections which is the dose approved by the US Food and Drug Administration (Bondy 2007). Growth hormone treatment though in higher doses, as mentioned above, has been shown to enhance growth even more in girls with TS but this many times leads to abnormally high IGF-I levels. Since the long-term effects of exceedingly high IGF-I concentrations during the growth period are not known and there is a theoretical potential of increasing the risk of cancer this should be avoided (Sas et al 1999a; Bannink et al 2006a; Park et al 2004; Ranke et al 2007).

Factors that seem to be most predictive of taller adult stature in TS individuals are related to the following: (1) taller mean parental height, (2) taller height at initiation of therapy, (3) the response to hGH during the first year of therapy, (4) mean dose of hGH/week, (5) taller height at the start of puberty and (6) age at the start of puberty (Wilson et al 1991; Welse et al 1993; Carel et al 1997; Hofman et al 1997; Ranke et al 2000; Reiter et al 2001; Quigley et al 2002; Bondy 2007; Ranke et al 2007; Rosenfeld 2007).

Some compounding factors that may explain the variability in the response of TS girls to hGH therapy are genomic imprinting and certain polymorphisms present in these girls. A recent study revealed that $72 \%$ of nonmosaic $45, X$ girls retain a maternal $X$ whereas $86 \%$ of nonmosaic $46, X, i(X q)$ girls carry an intact paternal X chromosome. By using a linear model which included age and height at the initiation of hGH therapy, the girls with a maternal $\mathrm{X}$ were shown to have a greater mean height gain than those with a paternal X. Interestingly, girls with a maternal X also had a smaller chance of having sensorineural hearing loss than the girls with a paternal X (Hamelin et al 2006). Also a protein polymorphism of the GH receptor (GHR) based on the genomic deletion of exon 3 (d3-GHR) has been linked to a significantly higher increment in height velocity of TS girls after the first year of treatment with high-dose recombinant hGH (Binder et al 2006).

The optimal age of initiation of hGH therapy is still not well established. Most physicians start hGH when the height drops well below the 5 th percentile on the growth chart, which is usually on the average around the age of 9 years (Saenger et al 1996). This results in a situation though where the TS 
girls are usually far behind their peers in height for most of their childhood adding frequently to their psychosocial isolation (Siegel et al 1998). A recent study from the Toddler Turner Study has added greatly to our insight on the age of initiation of hGH therapy in TS (Davenport et al 2007). This trial initiated hGH therapy $(0.35 \mathrm{mg} / \mathrm{kg} /$ week $)$ in TS girls at 2 years of age even before a significant deceleration in the height velocity was apparent. During the 2 years of therapy in these very young TS girls it was shown that there was a significant increase in height SDS (+1.1 SDS) in the treated girls compared with the non-treated age-matched controls. There were no significant differences between the bone ages of the two groups and as expected the IGF-I and IGFBP-3 levels increased in the hGH treated group within the normal concentrations for age. Following this study, it became apparent that the current thinking on the age of initiation of hGH therapy in girls with TS may need to be re-evaluated and new guidelines might need be instituted in order to possibly recommend hGH therapy at an earlier age in the TS girls instead of waiting for the deceleration in growth which is standard in TS. With earlier hGH therapy the girls with TS might have a chance to avoid the psychosocial isolation during childhood associated with the severe growth impairment of TS. The age of the initiation of hGH therapy though is still a matter of debate and further studies are still needed to conclusively address this issue.

\section{Oxandrolone therapy}

In the initial randomized, multicenter trial which was first reported in 1986, hGH was used alone or in combination with the androgen oxandrolone. After the completion of this trial, when the TS patients had attained their final height, this combined therapy was shown to have a significant impact on improving their growth and final adult height (Rosenfeld et al 1986). The 17 TS girls who completed this initial trial with $\mathrm{hGH}$ alone $(0.375 \mathrm{mg} / \mathrm{kg} /$ week $)$ attained a final height of $150.4 \mathrm{~cm}$, which was $8.4 \pm 4.5 \mathrm{~cm}$ above their projected adult heights. For the 43 TS girls treated with a combination of hGH $(0.375 \mathrm{mg} / \mathrm{kg} /$ week $)$ and oxandrolone $(0.125 \mathrm{mg} / \mathrm{kg} /$ week $)$, the mean adult height attained was $152.1 \mathrm{~cm}$, which was $10.3 \pm 4.7 \mathrm{~cm}$ taller than their projected adult heights (Rosenfeld et al 1998). Oxandrolone is not used very often currently since hormone replacement with estradiol in combination with hGH has been shown to be a more effective therapeutical regimen (Reiter et al 2001). Therapy using oxandrolone at a usual dose of $0.05 \mathrm{mg} / \mathrm{kg} /$ day is used mostly in TS patients with extreme short stature who start hGH therapy after 9 years of age. Therapy may be continued until a satisfactory height has been attained or until growth potential is limited (bone age $\geq 14$ years and growth velocity $<2 \mathrm{~cm} /$ year) (Bondy 2006).

\section{Estrogen therapy}

Most studies have shown that the final height of girls with TS seems to be maximized when estrogen therapy is combined with hGH. The optimal age of the initiation of estrogen therapy is at a normal pubertal age around 12 years of age (Reiter et al 2001; Quigley et al 2002). This is in contrast to the view that had prevailed till recently that delaying estrogen therapy till 15 years of age optimizes height potential (Rosenfeld et al 1986; Chernausek et al 2004). The reason for this dichotomy of views seems to be due to the fact that in some older studies younger TS girls were started on relatively large doses of conjugated estrogens in spite of the fact that it was clearly shown in 1983 that the effect of estradiol on growth has a biphasic effect, that is stimulatory at low doses and inhibitory at high doses (Ross et al 1983). The most current therapeutic trial of hGH and low-dose estrogen in TS girls, which had a duration of 20 years, decidedly showed that using very low doses of estradiol together with hGH at a normal pubertal age mimicking more closely the estrogen levels present in healthy girls at the time of puberty and increasing the estradiol dose as the TS girl progresses through puberty has a greatly enhancing effect on final adult height (Ross et al 2007). While early studies indicated that delaying estrogen replacement could improve final height outcomes in TS patients receiving hGH, this is not usually recommended, as delaying puberty in individuals who may already have a poor self-image may put them at a greater psycho-social disadvantage (Rosenfeld 2007). Starting estradiol at approximately 12 years of age also allows the TS girls to attain a normal bone mass which can only be attained if estradiol is started at the normal age of puberty and continued throughout puberty and adulthood (Hogler et al 2004). Health-related quality of life (HRQoL) evaluations of young women with TS who were treated long-term with hGH and sex steroid hormonal replacement therapy (HRT) showed that the women who had reached normal height and who had age-appropriate pubertal development had high scores on the HRQoL scales including "social functioning" and "role-emotional" scales (Bannink et al 2006b).

Many forms of estrogen are available for treating TS patients but oral estrogens have been most often used. Studies though show that transdermal and injectable depot forms of estradiol may be more physiologic alternatives to oral therapy (Ankarberg-Lindgren et al 2001; Piippo et al 2004; 
Rosenfield et al 2005; Soriano et al 2005; Bondy et al 2006). Replacement therapy is usually begun with one-tenth of the adult replacement dose. The initial dose (oral ethinlyestradiol: $2 \mu \mathrm{g} /$ day) is then gradually increased over 2 to 3 years in order to fully mimic physiologic increases of estradiol during normal puberty so that normal breast and uterine development may occur. The adult replacement doses which achieve estradiol levels in the normal range for young adult women are: oral ethinylestradiol: $20 \mu \mathrm{g} / \mathrm{day}$, transdermal estradiol: $0.1 \mathrm{mg} /$ day or injectable estradiol cypionate: $2.5 \mathrm{mg} / \mathrm{month}$ (Bondy et al 2006). The addition of progestin is recommended at least 2 years after starting estradiol or when breakthrough bleeding occurs. It is also imperative to teach the TS patient that estrogen therapy is usually required until the time of normal menopause (52-54 years of age) in order to maintain normal feminization and prevent osteoporosis in the future (Hogler et al 2004).

\section{Bone mineral density}

The effect of recombinant hGH therapy on bone mineral density (BMD) and body composition has also been studied in TS girls and it was found that GH treatment alone, without the combination with estradiol, had little effect on cortical or trabecular BMD although it did increase lean body mass and it reduced adiposity (Ari et al 2006). Also, whole body and lumbar spine BMD in adult TS patients who received only hGH therapy without hormone replacement therapy (HRT) with estradiol until the age of 17 showed decreased BMD which was not improved with HRT during adulthood since normal peak bone mass in these patients was never attained because of the delay in HRT (Suganuma et al 2003). This study emphasizes the importance of the initiation of estradiol therapy at a normal age of puberty in order to maximize peak bone mass at an appropriate age in order to avoid osteoporosis during adulthood.

\section{Safety of therapy}

The safety of hGH therapy in girls with TS has been an issue of much discussion. The effects of hGH on glucose metabolism has been addressed in many studies and although insulin levels increase significantly during hGH therapy in TS, compared to baseline, no glucose intolerance was uncovered and the insulin levels return to normal levels after the completion of the hGH therapy (Wilson et al 1991; Welse et al 1993; Sas et al 1999a; Van Teunenbrock et al 1999; Bannink et al 2006a). The impact of recombinant hGH therapy on the cardiovascular system has also been studied because many girls with TS have anatomic malformations affecting the heart, aorta and other major vessels, together with hypertension and abnormalities of heart rate, cardiac conduction and repolarization. Seven years of hGH treatment in TS girls was shown to have no adverse effects on left ventricular heart dimensions or blood pressure (Wilson et al 1991). Echocardiographical studies showed normal left ventricular morphology and function in GH-treated TS girls and magnetic resonance angiography found no deleterious effects of hGH treatment on aortic diameter or compliance (Sas et al 1999b; Radetti et al 2001; Bondy 2006; Vab deb et al 2006; Bondy 2007). Also no increased risk of neoplasia has been found in TS girls treated with hGH (Bondy 2007).

In conclusion, recombinant human GH therapy in combination with estradiol starting at the normal age of puberty is the treatment of choice for the treatment of short stature in girls with TS. Growth hormone therapy seems to be safe, with no adverse effects so far, on glucose metabolism or cardiac function or any association with neoplasms, but further studies are needed to give conclusive data on the issue of long-term safety. Nevertheless, most studies report that GH and estradiol therapy allows the girls with Turners Syndrome to attain normal adult height, pubertal development and bone mass and to maintain a good quality of life.

\section{Disclosures}

The author has no conflicts of interest to disclose.

\section{References}

Ankarberg-Lindgren D, Elfving M, Wikland KA, et al. 2001. Nocturnal application of transdermal estradiol patches produces levels of estradiol that mimic those seen at the onset of spontaneous puberty in girls. J Clin Endocrinol Metab, 86:3039-44.

Ari M, Bakalov VK, Hill S, Brody CA. 2006. The effects of growth hormone treatment and bone mineral density and body composition in girls with Turner syndrome. J Clin Endocrinol Metab, 91:4302-5.

Bannink EM, van Doorn J, Stijnen T, et al. 2006a. Free dissociable insulinlike growth factor I (IGF-I), total IGF-I and their binding proteins in girls with Turner syndrome during long-term growth hormone treatment. Clin Endocrinol (Oxf), 65:310-9.

Bannink EM, Raat H, Mulder PG, et al. 2006b. Quality of life after growth hormone therapy and induced puberty in women with Turner syndrome. J Pediatr, 148:95-101.

Binder G, Ranke MB, Martin DD. 2003. Auxology is a valuable instrument for the clinical diagnosis of SHOX haploinsufficiency in school-age children with unexplained short stature. J Clin Endocrinol Metab, 881:4891-6

Binder G, Baur F, Schweizer R, et al. 2006. The d3-growth hormone (GH) receptor polymorphism is associated with increased responsiveness to GH in Turner syndrome and short small-for-gestational-age children. $J$ Clin Endocrinol Metab, 91:659-64.

Blaschke RJ, Rappold G. 2006. The pseudoautosomal regions, SHOX and disease. Curr Opin Genet Dev, 16:233-9.

Blum, WF, Crowe BJ, Quigley CA, et al. 2007. Growth hormone is effective in treatment of short stature associated with short stature homeoboxcontaining gene deficiency: two-year results of a randomized, controlled multicenter trial. J Clin Endocrinol Metab, 92:219-28. 
Bondy CA, Van PL, Bakalov VK, et al. 2006. Growth hormone treatment and aortic dimensions in Turner syndrome. J Clin Endocrinol Metab, 91:1785-8.

Bondy CA; Turner Syndrome Consensus Study Group. 2007. Care of girls and women with Turner syndrome: A guideline of the Turner Syndrome Study Group. J Clin Endocrinol Metab, 92:10-25.

Carel JC, Mathivon L, Gendrel C, et al. 1997. Growth hormone therapy for Turner syndrome: evidence for benefit. Horm Res, 48:31-4.

Chernausek SD, Attie KM, Cara JF, et al. 2000. Growth hormone therapy of Turner syndrome: the impact of age of estrogen replacement on final height. Genentech, Inc. Collaborative Study Group. J Clin Endocrinol Metab, 85:2439-5.

Davenport ML, Punyasavatsut N, Gunther D, et al. 1999. Turner syndrome: a pattern of early growth. Acta Pediatr Suppl, 88:118-21.

Davenport ML, Crowe BJ, Travers SH, et al. 2007. Growth hormone treatment of early growth failure in toddlers with Turner syndrome: a randomized, controlled, multicenter trial. J Clin Endocrinol Metab, 92:3406-16.

Fechner PY, Davenport ML, Qualy RL, et al. Toddler Turner Study Group. 2006. Differences in follicle-stimulating hormone secretion between 45, X monosomy Turner Syndrome and 45, X/46 XX mosaicism are evident at early age. J Clin Endocrinol Metab, 91:4896-902.

Gravholt CH, Frystyk A, Flyvbjerg A, et al. 2001. Reduced free IGF-I and increased IGFBP-3 proteolysis in Turner syndrome: modulation by female sex steroids. Am J Physiol, 280: E308-E14.

Gravholt CH, Chen JW, Oxvig C, et al. 2006. The GH-IGF-IGFBP axis is changed in Turner syndrome: partial normalization by HRT. Growth Hormone IGF Res, 16(5-6):332-9.

Hamelin CE, Anglin G, Quigley CA, et al. 2006. Genomic imprinting in Turner syndrome: effects on response to growth hormone and on risk of sensorineural hearing loss. J Clin Endocrinol Metab, 91:3002-10.

Haverkamp F, Wolfle J, Zerres K, et al. 1999. Growth retardation in Turner syndrome: aneuploidy, rather than specific gene loss, may explain growth failure. J Clin Endocrinol Metab, 84:4578-82.

Ho KY, Evans WS, Blizzard RM, et al. 1987. Effects of sex and age on the 24-hour profile of growth hormone secretion in man: importance of endogenous estradiol concentrations. J Clin Endocrinol Metab, 64:51-8.

Hogler W, Briody J, Moore B, et al. 2004. Importance of estrogen on bone health in Turner syndrome: a cross-sectional and longitudinal study using dual-energy X-ray absorptiometry. J Clin Endocrinol Metab, 89:193-9.

Hofman P, Cutfiels WS, Robinson EM, et al. 1997. Factors predictive of response to growth hormone therapy in Turner's syndrome. J Pediatr Endocrinol Metab, 10:27-33.

Lyon AJ, Preece MA, Grant DB. 1985. Growth curve for girls with Turner syndrome. Arch Dis Child, 60:932-5.

Marchini A, Maritila T, Winter A, et al. 2004. The short stature homeodomain protein SHOX induces cellular growth arrest and apoptosis and is expressed in human growth plate chondrocytes. $J$ Biol Chem, 279:37103-14.

Massa GG, Vanderschueren-Lodeweyckx M, Malvaux P. 1990. Linear growth in patients with Turner syndrome: influence of spontaneous puberty and parental height. Eur J Pediatr, 149:246-50.

Munns CJF, Haase HR, Crowther LM, et al. 2004. Expression of SHOX in human fetal and childhood growth plate. J Clin Endocrinol Metab, 89:4130-5.

Nielsen J, Wohlert M. 1991. Chromosome abnormalities found among 34,910 newborn-children: results from a 13-year incidence study in Arhus, Denmark. Hum Genet, 87:81-3.

Park P, Cohen P. 2004. The role of insulin-like growth factor I monitoring in growth hormone-treated children. Horm Res, 62(Suppl 1):59-65.

Piippo S, Lenko H, Kainulainen P, et al. 2004. Use of percutaneous estrogen gel for induction of puberty in girls with Turner syndrome. $J$ Clin Endocrinol Metab, 89:3241-7.

Ogata T, Matsuo, N. 1993. Sex chromosome aberrations and stature:deduction of the principal factors involved in the determination of adult height. Hum Genet, 91:551-62.
Quigley CA, Crowe BJ, Anglin DG, et al. 2002. Growth hormone and low dose estrogen in Turner syndrome: Results of a United States multicenter trial to near-final height. J Clin Endocrinol Metab, 87:2033-41.

Radetti G, Crepaz R, Milanesi O, et al. 2001. Cardiac performance in Turner's syndrome patients on growth hormone therapy. Horm Res, 55:240-4.

Ranke MB, Lindberg A, Chatelain P, et al. 2000. Prediction of long-term response to recombinant human growth hormone in Turner syndrome: development and validation of mathematical models. KIGS International Board. Kabi International Growth Study. J Clin Endocrinol Metab, 85:4212-8.

Ranke MB, Lindberg A. 2007. Turner syndrome within KIGS including an analysis of 1146 patients grown to near adult height. In: Ranke MB, Price DA, Reiter EO (eds). Growth Hormone Therapy in Pediatrics 20 years of KIGS. Basel: Karger. p 332-9.

Rao E, Weiss B, Fukami M, Rump A, Niesler B, Mertz A, Muroya K, Binder G, Kirsch S, Winkelmann M, Nordisiek G, Heinrich U, Breuning MH, Ranke MB, Rosenthal A, Ogata T, Rappold GA. 1997. Pseudoautosomal deletions encompassing a novel homeobox gene cause growth failure in idiopathic short stature and Turner syndrome. Nat Genet, 16:54-63.

Rao E, Blaschke RJ, Marchini A, et al. 2001. The Leri-Weill and Turner syndrome homeobox gene SHOX encodes a cell-type specific transcriptional activator. Hum Mol Genet, 10:3083-91.

Reiter EO, Blethen SL, Baptista J, et al. 2001. Early initiation of growth hormone treatment allows age-appropriate estrogen use in Turner's syndrome. J Clin Endocrinol Metab, 86:1936-41.

Rongen-Westerlaken C, Corel L, van d, Broeck J, et al. 1997. Reference values for height, height velocity and weight in Turner's syndrome. Swedish Study Group for GH treatment. Acta Paediatrica, 86:937-42.

Rosenfeld RG, Hintz RL, Johanson AJ, et al. 1986. Methionyl human growth hormone and oxandrolone in Turner syndrome: preliminary results of a prospective randomized trial. J Pediatr, 109:936-43.

Rosenfeld RG, Attie KM, Frane J, et al. 1998. Growth hormone therapy of Turner's syndrome: Beneficial effect on adult height. $J$ Pediatr, 132:319-24.

Rosenfeld RG, 2007. In: Growth Hormone Therapy in Pediatrics - 20 years of KIGS. Ranke MB, Price DA, Reiter EO (eds). Basel, Karger. p. 326-31

Rosenfield RL, Perovic N, Devine N, et al. 1998. Optimizing estrogen replacement treatment in Turner syndrome. Pediatr, 102:486-8.

Rosenfield RL, Devine N, Hunold JJ, et al. 2005. Salutary effects of combining early very low-dose systemic estradiol with growth hormone therapy in girls with Turner syndrome. J Clin Endocrinol Metab, 90:6424-30.

Ross JL, Cassorla FG, Skerda MC, et al. 1983. A preliminary study of the effect of estrogen dose on growth in Turner syndrome. $N$ Engl J Med, 309:1104-6.

Ross JL, Long LM, Loriaux DL, et al. 1985. Growth hormone secretory dynamics in Turner syndrome. J Pediatr, 106:202-6.

Ross JL, Kowal K, Quigley CA, et al. 2005. The phenotype of short stature homeobox gene (SHOX) deficiency in childhood: contrasting children with Leri-Weill dyschondrosteosis and Turner syndrome. J Pediatr, 147:499-507.

Ross JL, Quigley CA, Cao D, et al. 2007. Early low-dose estrogen increases adult height gain in GH-treated patients with Turner syndrome (TS): results of a double-blind, randomized placebo-controlled clinical trial. Pediatric Academic Societies' Annual Meeting, Toronto, Canada, Abstract Number: 7515.5.

Rovet J, Ireland L. 1994. Behavioral phenotype in children with Turner syndrome. J Ped Psychol, 19:779-90.

Rovet J. 2004. Turner syndrome: a review of genetic and hormonal influences on neuropsychological functioning. Neurospychol Dev Cogn C Child Neurospychol, 10:262-79.

Saenger P. 1996. Turner's syndrome. N Engl J Med, 335:1749-54.

Sas TC, de Muinck Keizer-Schrama SM, Stijnen T, et al. 1999a Normalization of height in girls with Turner syndrome after long-term growth hormone treatment: results of a randomized dose-response trial. J Clin Endocrinol Metab, 84:4607-12. 
Sas TC, Comme-Dijkhuis AH, de Muinck Keizer Schrama SM, et al. 1999b. The effects of long-term growth hormone treatment on cardiac left ventricular dimensions and blood pressure in girls with Turner's syndrome. Dutch Working Group on Growth Hormone. J Pediatr, 135:470-46.

Siegel PT, Clopper R, Stabler B. 1998. The psychological consequences of Turner syndrome and review of the National Cooperative Growth Study psychological substudy. Pediatr, 102:488-91.

Soriano-Guillen L, Coste J, Ecosse E, et al. 2005. Adult height and pubertal growth in Turner syndrome after treatment with recombinant growth hormone. J Clin Endocrinol Metab, 90:5197-204.

Suganuma N, Furuhashi M, Hirooka T, et al. 2003. Bone mineral density in adult patients with Turner's syndrome: Analyses of the effectivemess of GH and ovarian steroid hormonal replacement therapies. Endocr J, 50:263-9.

Vab deb Berg J, Bannink EM, Wielopolski PA, et al. 2006. Aortic distensibility and dimensions and the effects of growth hormone treatment in the Turner Syndrome. The Amer J Card, 97:1644-9.

Van Pareren YK, de Muinck Keizer-Schrama SM, Stijnen T, et al. 2003. Final height in girls with Turner syndrome after long-term growth hormone treatment in three dosages and low dose estrogens, J Clin. Endocrinol Metab, 88:1119-25.

Van Teunenbrock A, Muinck Keizer-Schrama de SMPF, Aanstoot HJ, et al. 1999. Carbohydrate and lipid metabolism during various growth hormone dosing regimens in girls with Turner syndrome. Metab, 48:7-14.
Welse M, James D, Leitner CH, et al. 1993. Glucose metabolism in Ullrich-Turner syndrome: long-term effects of therapy with human growth hormone. Horm Res, 39:39-41.

Wilson DM, Rosenfeld RG, Genentech Turner Collaborative Group. 1991. Effect of GH and oxandrolone on carbohydrate and lipid metabolism. In: Ranke MB, Rosenfeld RG (eds). Turner syndrome: growth promoting therapies. Amsterdam: Elsevier Science Publishers BV. p. 269-74.

Zadik Z, Landau H, Chen M, et al. 1992. Assessment of growth hormone (GH) axis in Turner's syndrome using 24-hour integrated concentrations of GH, insulin-like growth factor-I, plasma GH-binding activity, GH binding to IM9 cells and GH response to pharmacological stimulation. J Clin Endocrinol Metab, 75:412-6.

Zinn AR, Ross JL: Critical regions for Turner syndrome phenotypes on the X chromosome. 2000. In: Saenger P, Pasquino AM (eds). Optimizing Health Care for Turner Patients in the 21st century. Amsterdam, Elsevier. p. 19-28.

Zinn AR, Roeltgen D, Stafanatos G, Ramos P, Elder FF, Kushner H, Kowal K, Foss JL. 2007. A Turner syndrome neurocognitive phenotype maps to X p. 22.3. Behav Brain Funct, 3:24. 
